\title{
Thoracic trident pigmentation in natural populations of Drosophila simulans: a comparison with $D$. melanogaster
}

\author{
P. Capy, \\ J. R. David and \\ A. Robertson*
}

\author{
Laboratoire de Biologie et Génétique Evolutives, \\ CNRS, 91198 Gif-sur-Yvette Cedex, France. \\ * Institute of Animal Genetics, University of \\ Edinburgh, West Main Road Edinburgh, EH9 3JN, \\ U.K.
}

By contrast with Drosophila melanogaster, wild living $D$. simulans adults generally do not exhibit a thoracic dark pigmentation with a trident shape. This trident however appears when development occurs at low temperature. A study of 26 natural populations from various parts of the world revealed a significant latitudinal cline, expressed only at $17^{\circ} \mathrm{C}$. The slope of this cline and the amplitude of the variations were, however, much lower than in $D$. melanogaster. Laboratory selection on equatorial and temperate populations of $D$. simulans led to the production of lines with a very dark trident expressed at all temperatures. Crosses between selected and unselected lines showed a main or partial influence of the $X$ chromosome, a maternal effect and a reversal of dominance according to growth temperature. Thus, $D$. simulans exhibits a large amount of genetic interpopulational variability which is not fully expressed among its geographic populations. For thoracic pigmentation, a clear contrast exists between the homogeneity of $D$. simulans natural populations and the great geographic variation found in $D$. melanogaster, an observation comparable to that made for other genetical traits in the two sibling species.

\section{INTRODUCTION}

Geographic differentiation in gene frequency may occur either as a consequence of local adaptations, or of stochastic events such as founder effects and genetic drift. Choosing between these interpretations must usually be based on indirect arguments. For a cosmopolitan species like Drosophila melanogaster the existence of parallel clines over different continents is a powerful argument in favour of the adaptive hypothesis (Endler, 1986). Moreover, when two closely related species, like $D$. melanogaster and D. simulans, which have similar geographic distributions and population dynamics (David and Tsacas, 1981), exhibit parallel genetical trends, the argument for adaptation becomes still stronger (Tantawy and Mallah, 1961; Parsons, 1983; Anderson and Oakeshott, 1984; Hyytia et al., 1985; Lemeunier et al., 1986).

Drosophila melanogaster is a very geographically differentiated species; less is known of its sibling (Lemeunier et al., 1986), although a few studies have suggested that the two may exhibit quite different patterns of genetic variability (Ashburner and Lemeunier, 1976; Dowsett and Young, 1982; Hyytia et al., 1985; Singh et al., 1987).
Thoracic trident pigmentation has long been known (Morgan and Bridges, 1919; Dubinin et al., 1934 cited in Merrel, 1981) as a highly polymorphic trait in natural populations of $D$. melanogaster. David et al. (1985) studied the phenotypic variability of that species, especially its response to environmental temperature and geographic variability. A very steep cline towards increased pigmentation was observed between 30 and $50^{\circ}$ of latitude on different continents. Here we show that, in spite of several analogies, the interpopulational variability of $D$. simulans is much lower than in D. melanogaster.

\section{MATERIALS AND METHODS}

\section{Natural populations}

Wild collected females were isolated to initiate isofemale lines. The F1 progeny (in almost all cases of more than ten lines) was then mixed to produce a mass culture which was analysed either immediately after collection or after a few generations in the laboratory. 


\section{Pigmentation score}

Flies were grown at low larval density on a killed yeast medium under controlled temperature. Two days after emergence, adults were examined with a binocular microscope and partitioned into four phenotypic classes, ranging from 0 (no visible trident) to 3 (dark trident). This qualitative procedure was used with $D$. melanogaster and produces very consistent results with different trained observers (David et al., 1985). For each population, temperature and set, 100 individuals were observed and the average score considered as a single measure.

\section{Selection procedure}

Thoracic pigmentation is far less pronounced in $D$. simulans than in $D$. melanogaster, and is generally not visible in flies grown at $25^{\circ} \mathrm{C}$. Selection was initiated by growing the flies at a low temperature $\left(14^{\circ} \mathrm{C}\right)$ which enforces dark pigmentation. About a quarter of the most pigmented individuals (never less than 20 individuals) were taken to produce the next generation. After a few generations, pigmentation increased and a higher selection temperature could be used, first $17^{\circ} \mathrm{C}$ and then room temperature (between $19^{\circ}$ and $25^{\circ} \mathrm{C}$ ). After about 30 generations, pigmentation did not increase further but selection was continued to stabilize the phenotype.

\section{RESULTS}

\section{Geographical variation in natural populations}

Drosophila simulans pigmentation scores for the available populations, at 17 and $25^{\circ} \mathrm{C}$ are given in table 1 . Within each population and temperature, male and female scores are highly correlated $(r=$ 0.96 and 0.92 at 17 and $25^{\circ} \mathrm{C}$ respectively). Females are on average slightly darker than males. At $25^{\circ} \mathrm{C}$, all populations are very light and phenotypically similar, and their limited variations are not correlated with latitude of origin $(r=0 \cdot 05)$. At $17^{\circ} \mathrm{C}$, on

Table 1 Origin and pigmentation scores of $D$. simulans populations. Average difference between sexes is significant at $17^{\circ} \mathrm{C}$ $(d=0.068 \pm 0.017)$ but not at $25^{\circ} \mathrm{C}(d=0.026 \pm 0.005)$. At each temperature, values of both sexes are highly correlated $\left(17^{\circ} \mathrm{C}\right.$ : $r=0.94 ; 25^{\circ} \mathrm{C}: r=0 \cdot 82$ )

\begin{tabular}{|c|c|c|c|c|c|c|c|c|}
\hline \multirow[b]{2}{*}{ Countries } & \multirow[b]{2}{*}{ Population } & \multirow[b]{2}{*}{ Latitude } & \multicolumn{3}{|l|}{$17^{\circ} \mathrm{C}$} & \multicolumn{3}{|l|}{$25^{\circ} \mathrm{C}$} \\
\hline & & & Female & Male & $d$ & Female & Male & $d$ \\
\hline France & Draveil & $48 \cdot 6^{\circ} \mathrm{N}$ & 0.91 & 0.75 & $+0 \cdot 16$ & 0.07 & 0.01 & +0.06 \\
\hline France & Villeurbanne & $45 \cdot 7^{\circ} \mathrm{N}$ & 0.94 & 0.90 & +0.04 & 0.04 & 0.03 & +0.01 \\
\hline France & Montpellier & $43 \cdot 4^{\circ} \mathrm{N}$ & 0.63 & 0.45 & $+0 \cdot 18$ & $0 \cdot 00$ & 0.00 & 0.00 \\
\hline France & Moulis & $42 \cdot 6^{\circ} \mathrm{N}$ & $0 \cdot 64$ & 0.53 & +0.11 & 0.03 & 0.03 & $0 \cdot 00$ \\
\hline France & Porquerolles & $43 \cdot 0^{\circ} \mathrm{N}$ & $1 \cdot 29$ & $1 \cdot 18$ & +0.11 & 0.08 & 0.01 & +0.07 \\
\hline France & Perpignan & $42 \cdot 4^{\circ} \mathrm{N}$ & $1 \cdot 00$ & 0.95 & +0.05 & 0.03 & 0.00 & +0.03 \\
\hline Greece & Athens & $37 \cdot 6^{\circ} \mathrm{N}$ & 0.63 & 0.65 & -0.02 & 0.02 & 0.04 & -0.02 \\
\hline Sicilly & Erice & $38.0^{\circ} \mathrm{N}$ & 0.62 & 0.35 & +0.27 & 0.02 & 0.00 & +0.02 \\
\hline California & Carmel & $36 \cdot 3^{\circ} \mathrm{N}$ & 0.91 & 0.86 & +0.05 & 0.00 & 0.00 & 0.00 \\
\hline Tunisia & Nasrallah & $35 \cdot 0^{\circ} \mathrm{N}$ & 0.74 & 0.64 & $+0 \cdot 10$ & 0.07 & 0.04 & +0.03 \\
\hline California & Pomona & $34 \cdot 0^{\circ} \mathrm{N}$ & 0.91 & $1 \cdot 03$ & $-0 \cdot 12$ & $0 \cdot 16$ & 0.09 & +0.07 \\
\hline Iraq & Baghdad & $33 \cdot 2^{\circ} \mathrm{N}$ & 0.71 & 0.71 & 0.00 & 0.08 & 0.03 & +0.05 \\
\hline Arizona & Tempe & $33 \cdot 2^{\circ} \mathrm{N}$ & 0.91 & 0.84 & +0.07 & $0 \cdot 04$ & 0.00 & +0.04 \\
\hline Canary Is. & Puerto Cruz & $32 \cdot 5^{\circ} \mathrm{N}$ & 0.89 & 0.82 & +0.07 & 0.05 & 0.00 & +0.05 \\
\hline Arizona & Tucson & $32 \cdot 1^{\circ} \mathrm{N}$ & $1 \cdot 03$ & $1 \cdot 15$ & $-0 \cdot 12$ & $0 \cdot 14$ & 0.07 & +0.07 \\
\hline Egypt & Alexandria & $31 \cdot 1^{\circ} \mathrm{N}$ & 1.02 & 1.03 & -0.02 & 0.09 & 0.05 & +0.04 \\
\hline Texas & Austin & $30 \cdot 2^{\circ} \mathrm{N}$ & $0 \cdot 80$ & 0.78 & +0.02 & 0.09 & 0.04 & +0.05 \\
\hline Hawaii & Hilo & $19 \cdot 4^{\circ} \mathrm{N}$ & 0.96 & 0.87 & +0.09 & $0 \cdot 01$ & 0.00 & +0.01 \\
\hline Botswana & Victoria Falls & $17 \cdot 6^{\circ} \mathrm{S}$ & 0.51 & 0.44 & +0.07 & 0.02 & $0 \cdot 00$ & +0.02 \\
\hline Polynesia & Moorea & $17 \cdot 3^{\circ} \mathrm{S}$ & $1 \cdot 12$ & 0.84 & +0.28 & 0.06 & 0.01 & $+0 \cdot 05$ \\
\hline Guiana & Cayenne & $4 \cdot 6^{\circ} \mathrm{N}$ & $0 \cdot 27$ & $0 \cdot 14$ & $+0 \cdot 13$ & 0.00 & 0.00 & 0.00 \\
\hline Congo & Brazzaville & $4 \cdot 0^{\circ} \mathrm{S}$ & $0 \cdot 32$ & 0.23 & +0.09 & 0.03 & 0.00 & +0.03 \\
\hline Seychelles & Mahé & $4.6^{\circ} \mathrm{S}$ & $0 \cdot 27$ & $0 \cdot 15$ & $+0 \cdot 12$ & $0 \cdot 01$ & 0.00 & +0.01 \\
\hline Tahiti & Papeete & $17 \cdot 4^{\circ} \mathrm{S}$ & 0.58 & 0.58 & $0 \cdot 00$ & 0.02 & 0.02 & 0.00 \\
\hline S. Africa & Johannesburg & $26 \cdot 0^{\circ} \mathrm{S}$ & 0.60 & 0.40 & $+0 \cdot 20$ & 0.00 & 0.00 & 0.00 \\
\hline S. Africa & Cape Town & $33 \cdot 0^{\circ} \mathrm{S}$ & 0.80 & $0 \cdot 82$ & -0.02 & 0.00 & $0 \cdot 01$ & -0.01 \\
\hline Mean & $(n=26)$ & & 0.752 & 0.678 & +0.068 & +0.044 & $0 \cdot 018$ & +0.026 \\
\hline
\end{tabular}


the other hand, a significant increase of trident pigmentation is seen $(r=0.68 ; P \leqq 0.05)$ as shown in fig. 1.

\section{Directional selection and crosses between dark and light strains}

Pigmentation intensity depends on growth temperature and a significant trident is observed only in flies reared at a low temperature, $14^{\circ} \mathrm{C}$ for tropical populations and $17^{\circ} \mathrm{C}$ for temperate populations (figs. 1 and 2). Do, in spite of their low level of phenotypic pigmentation, natural populations contain sufficient genetic variability to produce phenotypically dark flies? Two populations were selected, one from the tropics (Seychelles) and the other from a temperate country (Villeurbanne, France). In 30 generations, very dark flies were obtained from each, with a pigmentation score higher than 2.5 at $25^{\circ} \mathrm{C}$ (fig. 2 and table 2), thus demonstrating a large amount of hidden variability in each natural population.

Crosses were made between the selected lines and their original populations. The Seychellian flies were investigated over a broad range of growth temperature (fig. 2). Males and females of the selected line were very dark and their score is close

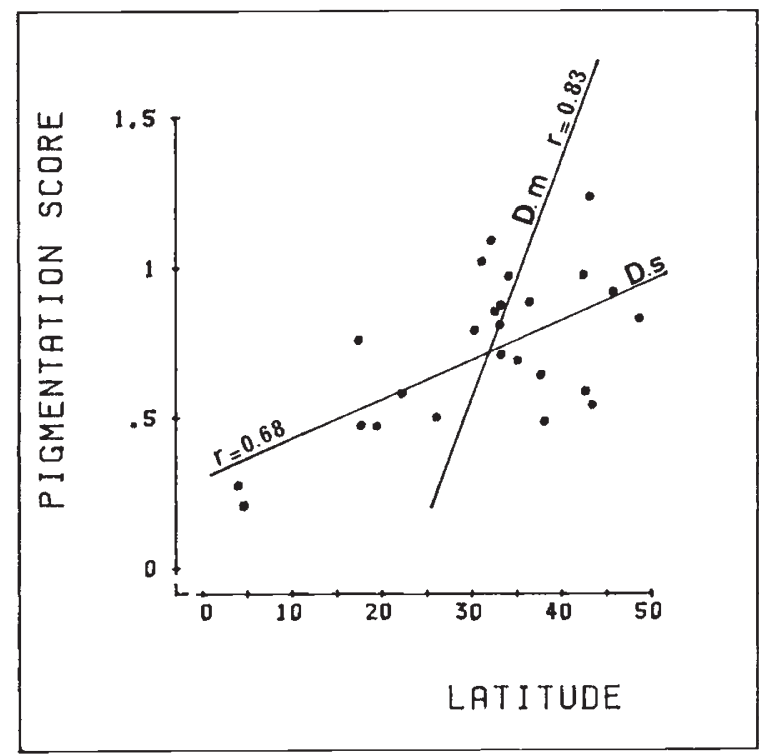

Figure 1 Relationship between pigmentation score of thoracic trident and latitude of origin in $D$. simulans. Flies were grown at $17^{\circ} \mathrm{C}$ (both sexes averaged). Points give the values for $D$. simulans (D.s.) populations $(r=0.68 ; b=0.010 \pm$ $0.003)$. For comparison the regression obtained in $D$. melanogaster (D.m.) between $30^{\circ}$ and $50^{\circ}$ of latitude is shown $(r=0.83 ; b=0 \cdot 090 \pm 0 \cdot 014)$.

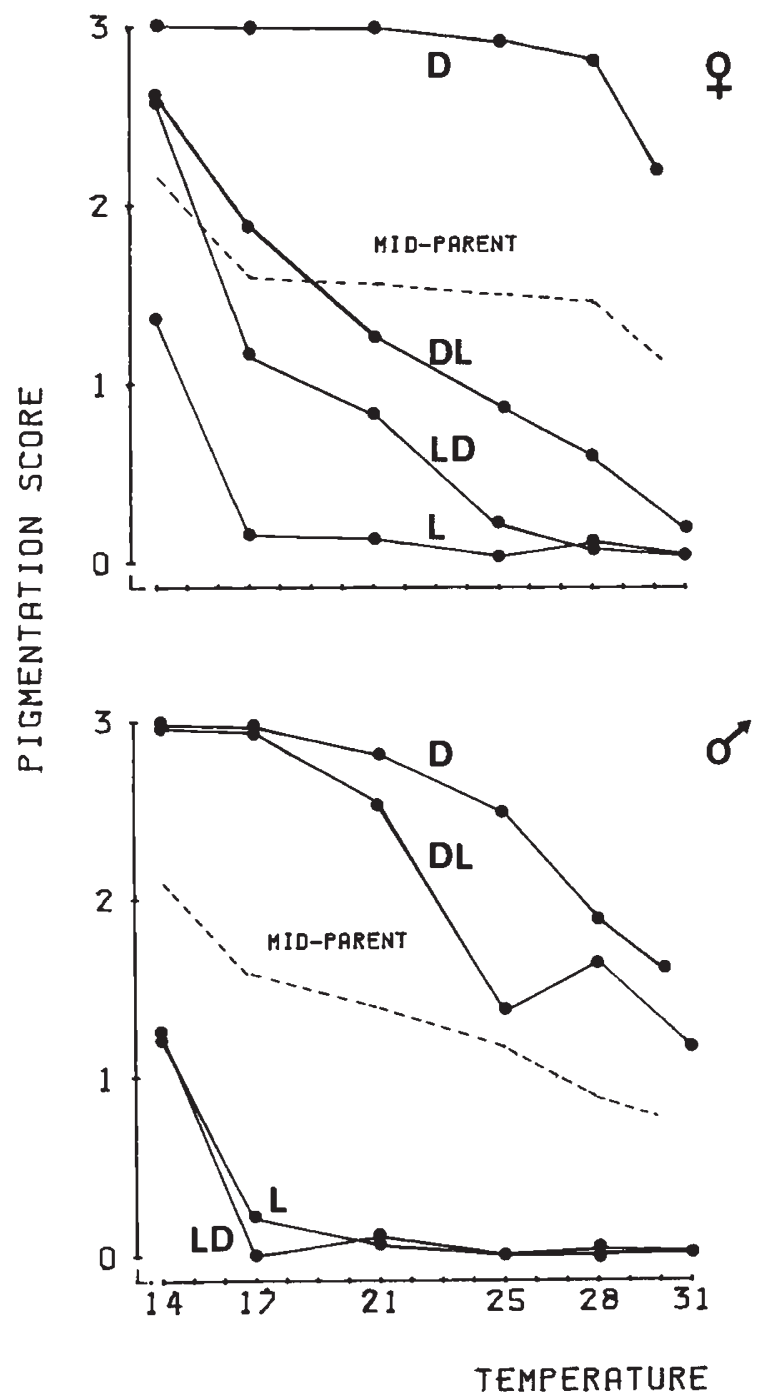

Figure 2 Relationship between growth temperature and pigmentation score in the Seychelles population of $D$. simulans. D: dark, selected line; L:light, unselected, natural strain; DL and LD: F1 individuals from respectively dark and light mothers. Confidence intervals are not shown but very small. The greatest standard error of all average values is 0.07 .

to the possible maximum value of 3 . Some decrease in pigmentation is however noticed with increasing temperature. Non-selected flies were very light, and a significant darkening was found only at $14^{\circ} \mathrm{C}$. F1 results differed greatly according to sex. In females which are genetically identical, a regular decrease of pigmentation is observed with increasing temperature, but the offspring of dark females are always darker than the offspring from the reciprocal cross, showing a maternal effect. A 
Table 2 Results from crosses between a selected dark line from Villeurbanne (France) and an unselected population of the same locality

\begin{tabular}{|c|c|c|c|c|}
\hline & \multicolumn{2}{|l|}{$17^{\circ} \mathrm{C}$} & \multicolumn{2}{|l|}{$25^{\circ} \mathrm{C}$} \\
\hline & Females & Males & Females & Males \\
\hline Selected parent (D) & 2.99 & 2.99 & $2 \cdot 64$ & $2 \cdot 58$ \\
\hline Unselected parent (L) & 0.63 & $0 \cdot 65$ & 0.02 & 0.04 \\
\hline Mid-parent & $1 \cdot 81$ & $1 \cdot 82$ & $1 \cdot 33$ & $1 \cdot 31$ \\
\hline $\begin{array}{l}\mathrm{F} 19 \mathrm{D} \times{ }^{\star} \mathrm{L} \\
\mathrm{F} 19 \mathrm{~L} \times \delta^{0} \mathrm{D}\end{array}$ & $\begin{array}{l}1 \cdot 56 \\
1.32\end{array}$ & $\begin{array}{l}2 \cdot 03 \\
1 \cdot 27\end{array}$ & $\begin{array}{l}1.04 \\
0.90\end{array}$ & $\begin{array}{l}1.29 \\
0.70\end{array}$ \\
\hline Difference between Fl's & $0 \cdot 24$ & $0 \cdot 76$ & $0 \cdot 14$ & 0.59 \\
\hline
\end{tabular}

modification of dominance with growth temperature is also noticed: at low temperatures, dark is dominant over light, while the reverse is true at high temperatures. F1 males, on the other hand, are almost phenotypically identical to their female parent, suggesting besides a possible maternal effect, an X-linked inheritance of pigmentation.

The French selected population was studied only at 17 and $25^{\circ} \mathrm{C}$ and the results are given in table 2. We again find a difference between the reciprocal $F 1$, which is more pronounced in males than in females. In females, the difference may be accounted for by a maternal effect. In males, a greater divergence presumably arises from an interaction between an $\mathrm{X}$ chromosome influence and a maternal effect. However, F1 males are not identical to those of their maternal strain suggesting that, in this European population, selection involved not only X-linked, but also autosomal genes.

\section{Comparison of $D$. simulans with D. melanogaster}

In D. melanogaster (David et al., 1985), the geographic variability of natural populations had to be split into two parts: between the equator and $20^{\circ}$ of north and south latitude, no significant correlation was observed; between $30^{\circ}$ and $50^{\circ}$ of latitude, a very steep cline was observed, at both $17^{\circ}$ and $25^{\circ} \mathrm{C}$ of growth temperature. The slope of the regression line in $D$. melanogaster was $0.090 \pm$ 0.014 and $0.055 \pm 0.011$ at $17^{\circ}$ and $25^{\circ} \mathrm{C}$ respectively.

Overall geographic variability is much lower in $D$. simulans than in D. melanogaster. For example, at $17^{\circ} \mathrm{C}$, the highest pigmentation score was 1.29 in the former species and 2.34 in the latter. The difference is still greater at $25^{\circ} \mathrm{C}(0 \cdot 16$ against $1 \cdot 32$ : fig. 3).

\section{DISCUSSION AND CONCLUSION}

Several of these observations on the thoracic pigmentation of $D$. simulans parallel those made on D. melanogaster (David et al., 1985). Thus, in crosses between dark and light lines, there is a maternal effect in the $F 1$ and a modification of dominance according to growth temperature, dark being dominant at a low temperature and recessive at high temperature. There is also a significant increase of pigmentation with latitude of origin. Such an analogy is a strong argument for assuming some adaptive significance of the cline (e.g., Anderson and Oakeshott, 1984). Several physiological responses may account for the pigmentation cline (see David et al., 1985) among which

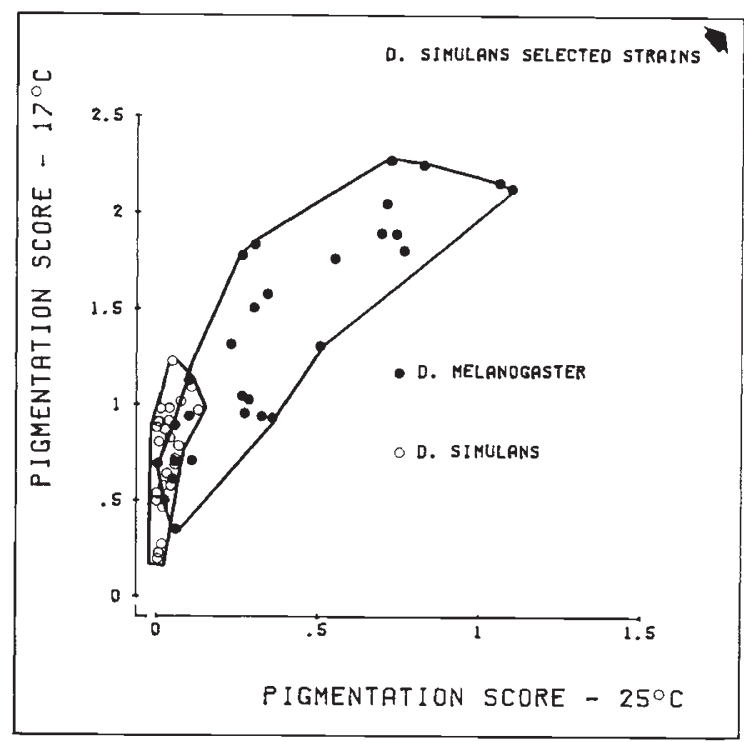

Figure 3 Relationship between pigmentation score at 17 and $25^{\circ} \mathrm{C}$ in the two sibling species. Note that the scores for D. simulans selected strains (see fig. 3 and table 2) are located outside the frame of the picture. 
some relationship with heat-desiccation tolerance is most likely. In the case of $D$. simulans, the fact that the cline is only expressed at a low temperature suggests that the adaptive phenotype concerns darker flies in countries where low temperatures are encountered. A possible explanation would be that during the cold season in temperate countries, a darker cuticule increases light absorption and improves the thermal balance of the fly (Jacobs, 1982). Also, an adaptive interpretation helps to understand the dominance reversal correlated to growth temperature.

However, besides these similarities, large differences exist between the two species. In $D$. melanogaster, the temperature response curve for pigmentation intensity is U-shaped with a minimum at about $25^{\circ} \mathrm{C}$, while, in $D$. simulans, there is no indication of any increase at high temperature. This difference may be due to different genetic bases for thoracic pigmentation. There is evidence that in D. melanogaster, several genes, carried by chromosomes 1,2 and 3 are involved but the major effect is autosomal (see David et al., 1985). In D. simulans, on the other hand, we have found a strong X-linked effect which could be due to a gene homologous to the pentagon gene ( ptg, $1-23 \cdot 2)$ of $D$. melanogaster.

The most striking divergence between the two species concerns the amount of variation between geographic populations, as shown in figs. 1 and 2 . A similar observation, i.e. a limited geographic variability in $D$. simulans, was already observed for a diversity of genetical traits, including chromosomal polymorphism (Ashburner and Lemeunier, 1976), allozymes (Hyytia et al., 1985; Watada et al., 1986a; Singh et al., 1987), morphometrics (Hyytia et al., 1985; Watada et al., 1986b) and alcohol tolerance (David and Bocquet, 1975). However, an opposite result, i.e., greater variability in $D$. simulans, was found for the inter-pulse interval of courtship songs (Kawanishi and Watanabe, 1980).

Intrapopulational variability is less clear since many traits remain to be studied. For several cases such as chromosomal polymorphism (Ashburner and Lemeunier, 1976), mitochondrial DNA polymorphism (Baba-Aïssa and Solignac, 1983 and personal communication), bidimensional electrophoretic polymorphism (Onishi et al., 1983), and the number of repeated genomic sequences (Dowsett and Young, 1982), the genetic diversity is much lower in D. simulans. For quantitative, morphological or physiological traits, the results are usually not clear and further work is needed. In the present study, thoracic pigmentation, con- sidered as a quantitative trait, responded quickly to directional selection, thus demonstrating the presence of a large amount of genetic diversity within natural populations.

Comparative ecological genetic studies suggest that, in spite of their similar colonizing ability and ecological success, the two sibling species exhibit different genetic structures. $D$. simulans may have colonized the world more recently than $D$. melanogaster, after a founder effect (Baba Aïssa and Solignac, 1983; Singh et al., 1987) and has thus had less time to adapt itself to local conditions. However, other interpretations may also be suggested, including a narrower and more uniform ecological niche in $D$. simulans than in $D$. melanogaster. There may also be genomic constraints opposing the diversification of the $D$. simulans populations. Further investigations involving more numerous genetical traits are obviously needed to understand the genetic strategies of the two sibling species.

\section{REFERENCES}

ANDERson, P. R. AND OAKeshott, J. C. 1984. Parallel geographical pattern of allozyme variation in two sibling Drosophila species. Nature 308, 729-731.

ASHBURNER, M. AND LEMEUNIER, F. 1976. Relationship within the melanogaster species subgroup of the genus Drosophila (Sophophora). I. Inversion polymorphisms in Drosophila melanogaster and Drosophila simulans. Proc. $R$. Soc. London Ser. B, 193, 137-157.

BABA-AISSA, F. AND SOLIGNAC, M. 1984. La plupart des populations de Drosophila simulans ont probablement pour ancêtre une femelle unique dans un passé récent. C.R. Acad. Sci. Ser. 3, 299, 289-292.

DAVID, J. R. AND BOCQUET, C. 1975. Similarities and differences in latitudinal adaptation of two Drosophila sibling species. Nature, 257, 588-590.

DAVID, J. R. AND TSACAS, L. 1981. Cosmopolitan, subcosmopolitan and widespread species: different strategies within the Drosophilid family (Diptera). C.R. Soc. Biogéog., 57, 11-26.

DAVID, J. R., CAPY, P., PAYANT, V. AND TSAKAS, S. 1985. Thoracic trident pigmentation in Drosophila melanogaster: differentiation of geographical populations. Génét Sél. Evol., 17 (2), 211-224.

DOWSETT, P. A. AND YOUNG, M. W. 1982. Differing level of dispersed repetitive DNA among closely related species of Droscphila. Proc. Natl. Acad. Sci. U.S.A., 79, 4570-4574.

ENDler, J. A. 1986. Natural Selection in the Wild. Princeton Univ. Press, Princeton.

HYYTIA, P., CAPY, P., DAVID, J. R. AND SINGH, R. S. 1985. Enzymatic and quantitative variation in European and African populations of Drosophila simulans. Heredity, 54, 209-217.

JACOBS, M. E. 1982. Beta-alanine and tanning polymorphisms. Comp. Biochem. Physiol., 72B, 173-177.

KAWANASHI, M. AND WATANABE, K. 1980. Genetic variations of courtship song of Drosophila melanogaster and Drosophila simulans. Jpn. J. Genet., 55, 235-240. 
LEUMEUNIER, F., DAVID, J. R., TSACAS, L. AND ASHBURNER, M. 1986. The melanogaster species group. In Ashburner, M., Carson, K. L. and Thompson, Jr, J. N. (eds) The Genetics and Biology of Drosophila, Vol. 3e. Academic Press, New York, pp. 147-256.

MERREL, D. J. 1981. Ecological Genetics. Longman, London. MORGAN, T. H. AND BRIDGES, C. B. 1919. The inheritance of a fluctuating character. J. Gen. Physiol., 1, 639-643.

OHNISHI, S., LEIGH-BROWN, A. J., VOELKER, R. A. AND LANGLEY, C. H. 1982. Estimation of genetic variability in natural populations of $D$. simulans by two dimensional and starch gel electrophoresis. Genetics, 100, 127-136.

PARSONS, P. A. 1983. The Evolutionary Biology of Colonizing Species. Cambridge Univ. Press, Cambridge.
SINGH, R. S., CHOUDHARY, M. AND DAVID, J. R. 1987. Contrasting patterns of geographic variation in cosmopolitan sibling species $D$. melanogaster and $D$. simulans. Biochem. Genetics, 117, 27-40.

TANTAWY, O. A. AND MALlaH, G. S. 1961. Studies on natural populations of Drosophila. I. Heat resistance and geographic variation of Drosophila melanogaster and $D$. simulans. Evolution, 15, 1-14.

WATADA, M., TOBARI, Y. N. AND OHBA, S. 1986a. Genetic differentiation in Japanese populations of Drosophila simulans and Drosophila melanogaster. I. Allozyme polymorphisms. Jpn. J. Genet., 61, 253-269.

WATADA, M. OHBA, S. AND TOBARI, Y. N. Q. $1986 b$. Genetic differentiation in Japanese populations of Drosophila simulans and Drosophila melanogaster. II. Morphological variations. Jpn. J. Genet., 61, 469-480. 